\title{
MARKETING VISUAL: A CONSTANTE BUSCA POR ATENÇÃO DOS CONSUMIDORES.
}

\section{VISUAL MARKETING: THE CONSTANT SEARCH FOR CONSUMER'S ATTENTION.}
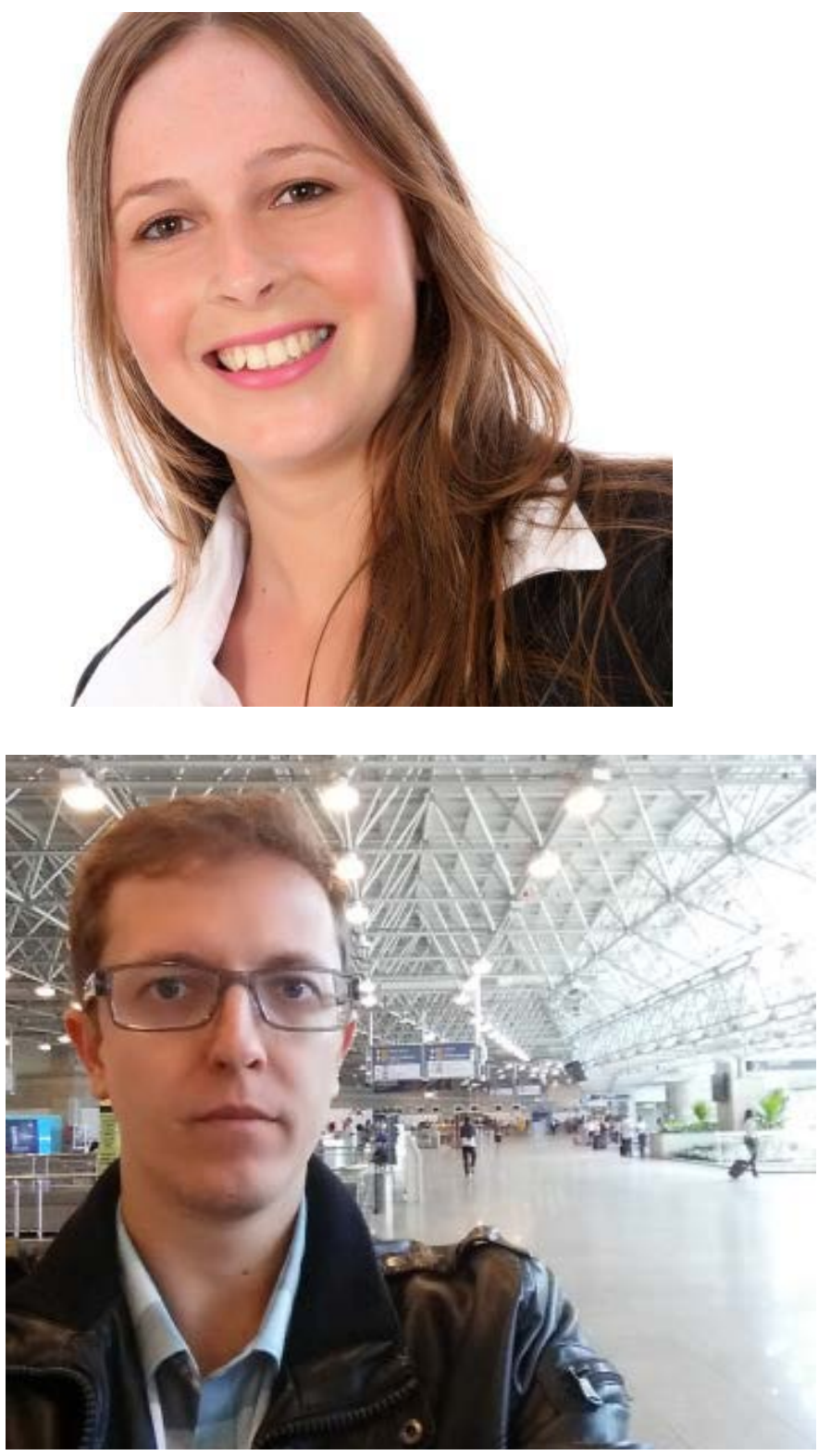

\section{Suele Camatini}

Mestranda em Administração pela Universidade Federal de Santa Catarina (UFSC)

Programa de Pós-Graduação em Administração da Universidade Federal de Santa Catarina (UFSC) suele.camatini@gmail.com

\section{Martin de La Martiniere Petroll}

Doutor em Administração pelo Programa de PósGraduação em Administração da Universidade Federal do Paraná (UFPR)

Professor do Departamento de Ciências da Administração do Centro Socioeconômico da Universidade Federal de Santa Catarina (UFSC) martin.petroll@ufsc.br 

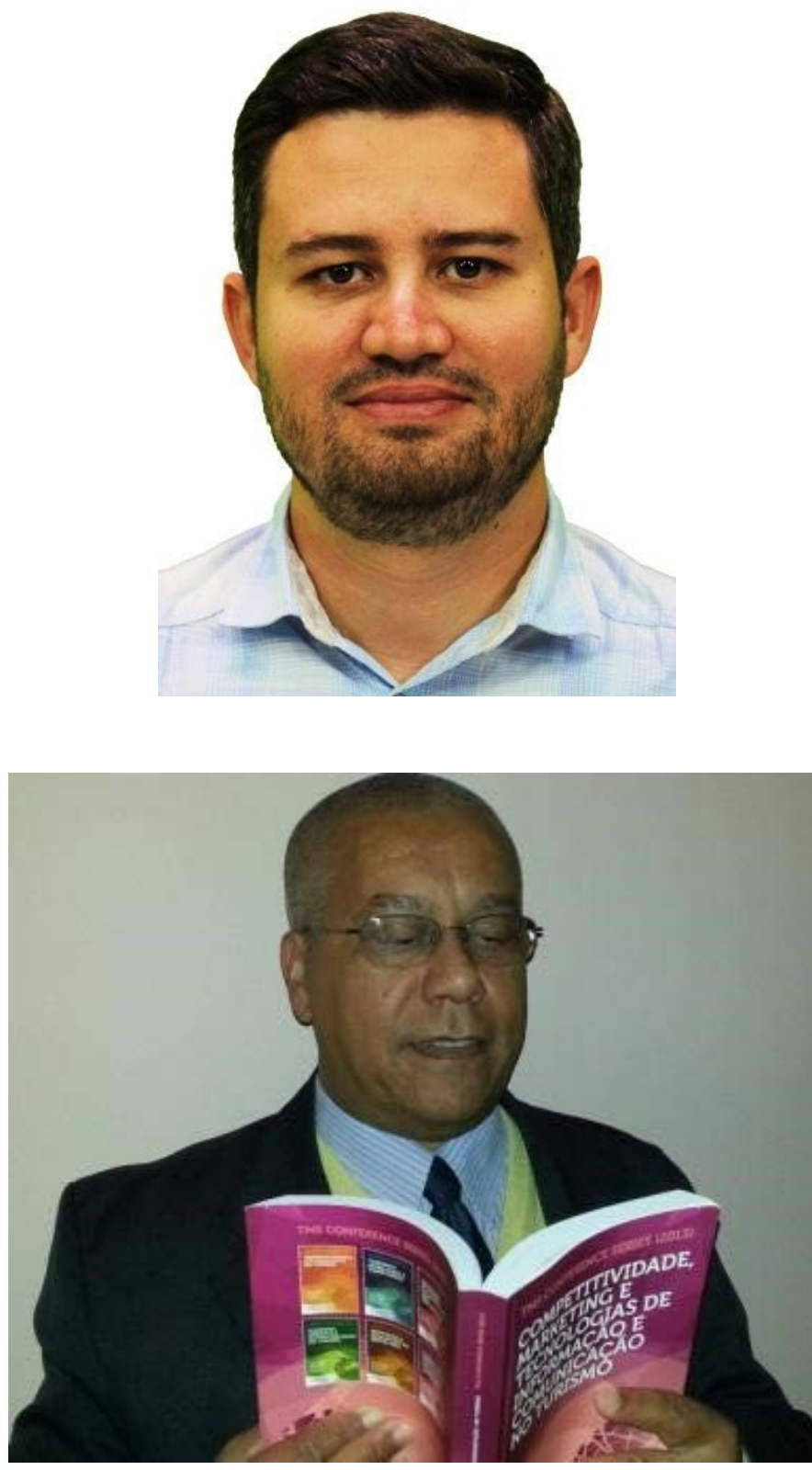

\section{Elder Semprebon}

Doutor em Administração pelo Programa de PósGraduação em Administração da Universidade Federal do Paraná (UFPR)

Professor do Departamento de Administração da Universidade Federal do Paraná (UFPR) elder.semprebon@gmail.com

\section{Rudimar Antunes da Rocha}

Pós-Doutorado em Administração pela Escola de Economia e Gestão da Universidade do Minho Braga/Portugal

Professor PhD., do Departamento de Administração, da Universidade Federal de Santa Catarina (UFSC)

rrudimar@hotmail.com

\section{RESUMO}

Conquistar a atenção dos consumidores é o intuito de qualquer organização. Mas isso não é fácil de ser feito já que, muitas vezes, os consumidores não estão aptos a processar conscientemente os estímulos visuais aos quais estão expostos. Nessa situação, o marketing visual mostra-se um importante aliado das organizações e de pesquisadores, oportunizando a utilização de sinas visuais e símbolos comerciais e não comerciais de modo estratégico a fim de conceder mensagens e experiências desejáveis para os consumidores. Partindo dessa perspectiva, o presente artigo analisou, através 
do método bibliométrico, 42 estudos sobre marketing visual publicados nos últimos 20 anos (1995-2015). Como resultados, foram apresentados os principais achados dos mesmos, além de sugeridos rumos para futuras investigações em marketing visual.

\section{PALAVRAS-CHAVE}

Marketing Visual. Atenção. Comportamento do Consumidor.

\section{ABSTRACT}

Gain the attention of consumers is the goal of any organization, however, it is not easy because sometimes consumers are not able to consciously handle much of the visual stimuli to which they are exposed. In this situation, the visual marketing proves to be an important ally for organizations and researchers, providing opportunities for the use of visual symbols resins and commercial and non-commercial strategically in order to provide messages and desirable experiences for consumers. From this perspective, this article used bibliometrics method and analyzed 42 studies of visual marketing published in the last 20 years (19952015). Results are shown as well as suggestions of directions for future research in visual marketing.

\section{KEYWORDS}

Visual Marketing. Attention. Consumer Behavior.

\section{INTRODUÇÃO}

Os consumidores estão expostos diariamente a um bombardeio de propagandas na televisão, em jornais, em revistas, nos outdoors, na Internet ou até mesmo em embalagens de produtos, em uniformes, nas camisetas, entre outros (WEDEL; PIETERS, 2008; KRISHNA, 2012). Segundo Ember (2015), foram investidos, em 2015, cerca de US\$ 503 bilhões em propaganda no mundo, com perspectiva de crescimento de 4,6\% em 2016, chegando a US\$ 526 bilhões e de US\$ 719 bilhões até o fim de 2019 (eMARKETER, 2015).

No Brasil, em 2014 foram investidos cerca de R\$ 121 bilhões em propaganda, um crescimento de $8 \%$ em relação ao ano anterior. Deste 
montante, $R \$ 67$ bilhões foram para a TV aberta, $R \$ 17$ bilhões para o jornal e R\$ 11 bilhões para a TV por assinatura. Em 2015, mesmo com a crise econômica no país, houve um acréscimo de $0,8 \%$ no primeiro semestre em comparação com o de 2014. Destacam-se os setores do comércio e varejo como os que mais investiram em comunicação (19\%), seguido pelo de serviços ao consumidor e o de higiene pessoal e beleza (ambos com 11\% de participação cada) (IBOPE MEDIA, 2015).

Em um primeiro momento, presume-se que, pelos investimentos vultosos supracitados, a comunicação via propaganda é efetiva para as organizações. Todavia, sabe-se que o consumidor não é capaz de assimilar todas as propagandas que são veiculadas (PIETERS; WEDEL, 2004), porque a sua atenção é limitada (DAVENPORT; BECK, 2001). Ou seja, devido à capacidade cerebral limitada, conhecida como gargalo da atenção, muitos dos estímulos sensoriais expostos ao consumidor não atingem a consciência do público-alvo almejado (MILOSAVLJEVIC; CERF, 2008). Portanto, há uma dificuldade cada vez maior em atrair a atenção do consumidor, reduzindo o poder do marketing (SACHARIN, 2001) com a diminuição da efetividade da propaganda sobre o comportamento do consumidor, resultando em consequentes perdas financeiras para a empresa e, finalmente, no descumprimento das suas metas de marketing (PIETERS; WEDEL, 2004).

Para enfrentar esse problema, inúmeras organizações estão utilizando o marketing visual (WEDEL; PIETERS, 2006), já que se sabe que estímulos sensoriais, quando bem aplicados, podem influenciar positivamente na tomada de decisão do consumidor e, por conseguinte, na sua propensão a gastar (SOARS, 2009). O marketing visual tem um aliado, a tecnologia, que está colaborando com os métodos tradicionais de pesquisa a partir de instrumentos como, por exemplo, a Ressonância Magnética Funcional ${ }^{1}$ (fMRI) e o Eye tracking ${ }^{2}$, os quais visam entender o inconsciente do consumidor sobre os estímulos de marketing no "mundo real" (WEDEL; PIETERS, 2006).

Sabe-se, por exemplo, que diversas empresas, como é o caso das multinacionais Microsoft, Google, IBM e Unilever estão utilizando aquelas tecnologias em conjunto com o marketing visual com o objetivo de realmente conhecer o seu consumidor (WEDEL; PIETERS, 2006). O mesmo deve ser feito pela academia. Sendo assim, o presente estudo realizou um levantamento da produção científica dos últimos vinte anos (de 1995 a 
2015) sobre marketing visual com a finalidade de contribuir tanto para uma melhor compreensão a respeito do tema quanto para a identificação de possíveis lacunas a serem preenchidas por estudos vindouros.

\section{REFERENCIALTEÓRICO}

Inicialmente, para um melhor entendimento sobre marketing visual, faz-se necessário a compreensão sobre marketing sensorial. O marketing sensorial pode ser entendido como a maneira com que o marketing "envolve os sentidos dos consumidores e afeta a sua percepção, avaliação e comportamento" (KRISHNA, 2010, p. 38, tradução nossa). Isso porque se sabe que os sentidos humanos - visão, audição, olfato, tato e paladar - são imprescindíveis para as experiências dos indivíduos nos diversos processos de compra e de consumo (AGAPITO; MENDES;VALLE, 2013), já que o mundo é experimentado por meio daqueles sentidos e suas experiências subjetivas e informações sensoriais vivenciadas denotam um papel essencial na ação e cognição humanas (KRISHNA; SCHWARZ, 2014).

O marketing sensorial, portanto, atua a fim de conceber gatilhos subconscientes que definem as percepções do indivíduo a respeito de um produto, por exemplo (KRISHNA, 2012). Sob um enfoque prático, almeja-se desenvolver pontos de contato sensoriais com os consumidores com o intuito de diferenciar-se no mercado (SPENCE et al., 2014), até porque, quanto mais sensorial for a experiência presenciada pelo consumidor, mais envolvente ela será (KRISHNA, 2010).

Dentre os sentidos humanos, a visão é o mais empregado para compreender o consumidor quanto ao seu comportamento de aquisição e uso de produtos e serviços (HULTÉN, 2011). Não há motivos, todavia, para subestimar a importância dos demais sentidos, mas é fato que os estímulos visuais dominam os estudos e uso pelas organizações (WEDEL; PIETERS, 2006). Tanto é verdade que são os olhos os responsáveis por guiar os consumidores no momento em que estão investigando, pesquisando e tomando suas decisões a respeito das marcas de produtos e serviços.

Todavia, a alta concorrência entre as empresas aliada com a pouca atenção (gargalo da atenção) por parte dos consumidores a estímulos visuais requer uma melhor compreensão de como e quando aqueles dedicam atenção aos estímulos comerciais (ROSBERGEN; PIETERS; WEDEL, 
1997). Destarte, é necessário entender o marketing visual, considerado por Wedel e Pieters (2008, p. 01, tradução nossa) como sendo a"utilização estratégica por parte das empresas de sinas visuais e símbolos comerciais e não comerciais para entregar mensagens e experiências desejáveis e/ou úteis para os consumidores".

O marketing visual está estabelecido na interseção entre a ciência da visão, a psicologia cognitiva e a psicologia social e seu objetivo consiste em compreender e avaliar a influência das ações e estímulos de marketing visual sobre o consumidor, bem como os mecanismos de processamento visuais subjacentes aos seus comportamentos (WEDEL; PIETERS, 2008). Isso porque a atenção visual é ponto fundamental para a eficácia da propaganda (BRASEL; GIPS, 2008). Para Pieters e Wedel (2004), propagandas que capturam a atenção atraem o consumidor, fazendo com que ele as selecione de seu ambiente, além de retê-las, ocasionando, dessa forma, uma maior atenção por parte do consumidor à propaganda e aos seus elementos. Para que isso aconteça, há tanto os fatores "de baixo para cima" (bottom-up factors) como os fatores "de cima para baixo" (top-down factors). Os primeiros se referem aos estímulos (atributos da propaganda como a cor, o tamanho, entre outros), já os outros, ao indivíduo e ao processo, influenciados pelo envolvimento com o produto, sua motivação e familiaridade com o mesmo ou com a propaganda (PIETERS; WEDEL, 2004).

Para tudo isso, os movimentos dos olhos são capazes de indicar informações relevantes sobre os processos fisiológicos. Segundo Pieters e Warlop (1999) e Pieters, Rosbergen e Wedel (1999), a atenção revelada pelos movimentos motores observáveis dos olhos efetua um caminho a ser percorrido, sendo que a fixação dos olhos representa a forma mais eficiente para um indivíduo no que diz respeito à obtenção de informação do ambiente do qual faz parte e, por conseguinte, mostra-se o momento mais adequado para mensurar a atenção do consumidor (PIETERS; ROSBERGEN; WEDEL, 1999). Assim, é indiscutível a relação entre a atenção e a movimentação dos olhos (RAYNER; CASTELHANO, 2008), pois "os olhos não mentem. Se você quer saber no que as pessoas estão prestando atenção, siga onde elas estão olhando" (DAVENPORT; BECK, 2001, p. 19, tradução nossa).

Por fim, Wedel e Pieters (2008) consideram que, mesmo predominando a prática do marketing visual aliada a investimentos cada vez mais vultosos também em tecnologias como o Eye tracking, o conhecimento e 
os esforços de marketing são ainda limitados e dispersos.

\section{METODOLOGIA}

Objetivando contribuir para uma maior compreensão do marketing visual, utilizou-se o método bibliométrico da produção científica sobre o tema a partir do levantamento com os seguintes critérios: (a) artigos publicados entre os anos de 1995 a 2015; (b) apenas publicações provenientes de periódicos ou revistas científicas; (c) os temas principais de investigação dos artigos deveriam estar relacionados com o sentido básico humano da visão e questões da área de marketing; e (d) quantidade de vezes em que o referido artigo selecionado foi citado por outros estudos ou a sua pertinência e relevância para a compreensão do marketing visual. Como contexto para a busca dos artigos optou-se pelas seguintes bases de dados nacionais e internacionais: Web of Science, EBSCO, Spell e Scopus.

Além disso, os artigos foram selecionados a partir de uma revisão sistemática sugerida por Dybå e Dingsøyr (2008) e operacionalizada em quatro estágios, apresentados no Quadro 1.

Quadro 1 - Estágios da Pesquisa nas Bases de Dados
\begin{tabular}{|l|l|c|}
\hline \multicolumn{1}{|c|}{ Estáglos } & \multicolumn{1}{|c|}{ Descriçåo } & N \\
\hline Estágio 1 & $\begin{array}{l}\text { Identificar artigos relevantes para o estudo nas bases de dados } \\
\text { selecionadas (Web of Science, EBSCO, Spell e Scopus). }\end{array}$ & 935 \\
\hline Fstágio 2 & Excluir artigns com base nos títulos. & 175 \\
\hline Estágio 3 & Excluir artigos com base nos resumos. & 84 \\
\hline Estágio 4 & Obter dos artigos e realizar leitura crítica. & 42 \\
\hline Total de $\Lambda$ rtigos Selecionados & $\mathbf{4 2}$ \\
\hline
\end{tabular}

Para a realização da revisão sistemática, primeiramente foram definidas as principais palavras-chave para o levantamento dos artigos, localizadas tanto no título, nos termos ou até mesmo no resumo dos trabalhos. As palavras-chave escolhidas foram: "marketing", "visual", "atenção", "attention”, "propagandas", "advertising", "embalagem", "package", "atmosfera" e "atmosphere". Com isso, foram encontrados um total de 935 artigos nas bases de dados. Em seguida, refinou-se a amostra por meio da leitura de todos os títulos, resultando em um total de 175 trabalhos escolhidos para o próximo estágio. Seguindo as recomendações de Dybå e Dingsøyr (2008), optou-se por excluir os 37 artigos repetidos. Além disso, durante o estágio 3, de leitura dos resumos, considerou-se, para a escolha dos artigos, aqueles cujos 
resumos estivessem condizentes com o tema do marketing visual e de subtemas voltados às palavras-chave anteriormente mencionadas, resultando em 84 estudos. Finalmente, no quarto e último estágio realizou-se a leitura integral de todos os 84 estudos, considerando-se aqueles mais pertinentes para a pesquisa, resultando em 42 artigos que atenderam a todos os critérios recomendados na revisão sistemática por Dybå e Dingsøyr (2008).

\section{RESULTADOS}

Objetivando a compreensão da evolução das publicações nacionais e internacionais sobre marketing visual, realizou-se, por intermédio de uma contagem simples, a análise da quantidade de artigos publicados a cada ano (entre 1995 e 2015). Os primeiros artigos encontrados no levantamento são do ano de 1997 e os últimos são do ano de 2015, destacando-se que, a partir de 2007, houve um aumento considerável nos estudos publicados sobre marketing visual, principalmente estudos de fora do Brasil e apenas um deles - Petroll e Prado (2015) - oriundo de publicação nacional, demonstrando uma carência de estudos acadêmicos sobre marketing visual no país.

Com relação aos periódicos em que estavam publicados os 42 artigos restantes levantados entre 1995 e 2015 pelo presente estudo, foram identificadas 26 revistas, destacando-se o Journal of Marketing (5 artigos), Psychology \& Marketing (4 artigos), Journal of Consumer Research (4 artigos) e Journal of Consumer Psychology (3 artigos). Dentre os 42 artigos, 5 são ensaios teóricos e os demais 37 são estudos teórico-empíricos. No que diz respeito aos 5 ensaios teóricos, o Quadro 2 apresenta os nomes dos respectivos autores, o ano de publicação, as principais teorias e constructos abordados e as principais contribuições para a teoria do marketing visual. 


\section{Quadro 2. Ensalos Té́ricos Selectonados}

\begin{tabular}{|c|c|c|}
\hline $\begin{array}{l}\text { Autorcs } \\
\text { (ann) }\end{array}$ & $\begin{array}{c}\text { Principais Teorias e } \\
\text { Constructos }\end{array}$ & Principals Contribuiçðes \\
\hline $\begin{array}{l}\text { Grossman e } \\
\text { Wisenhlit } \\
\text { (1999) }\end{array}$ & $\begin{array}{l}\text { *Aprendiaggem A ssoriativa; } \\
\text { "Condicinnamento Classico, } \\
\text { * Fovolvimenta. }\end{array}$ & 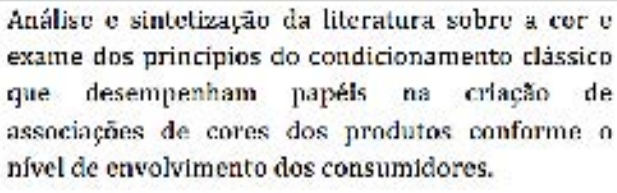 \\
\hline $\begin{array}{l}\text { Milosavijevic } \\
\text { e Cerf [2000] }\end{array}$ & $\begin{array}{l}\text { "Modelas Computacionais } \\
\text { de Atençäo Visual; } \\
\text { "Atençäo Visual Bottom-up; } \\
\text { "Atençäo Visual Top-down. }\end{array}$ & 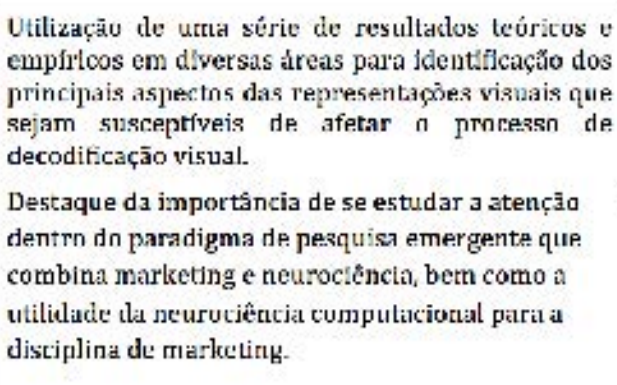 \\
\hline $\begin{array}{l}\text { Libreculue, } \\
\text { Pialricke Mil en } \\
\text { (2013) }\end{array}$ & $\begin{array}{l}\text { "Percepção e Associaçăo } \\
\text { das Cores; } \\
\text { * Tomada de Decisáo; } \\
\text { * Influáncias Culturais. }\end{array}$ & $\begin{array}{l}\text { Chamain a atençāo para a importáncia da pesquisa } \\
\text { de cores no marketing e a necessidatle de } \\
\text { Investigaços mals profundas. Além disso, } \\
\text { oferecem insights de lacunas na literatura por } \\
\text { intermédin de uma série de prnpostas para futuras } \\
\text { pesquisas. }\end{array}$ \\
\hline Rosa (2015) & $\begin{array}{l}\text { *Atençäo Visual; } \\
\text { * Muvimentu dus olhos. }\end{array}$ & 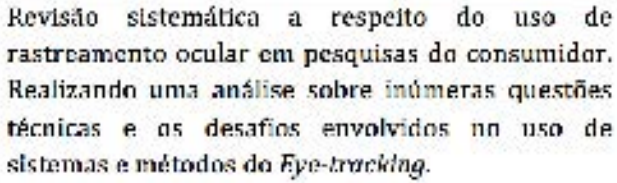 \\
\hline
\end{tabular}

Fonte: Flahorado peing sutores.

Tais estudos abrangem constructos e teorias como: aprendizagem associativa, envolvimento, condicionamento clássico, processos de decisão, representações visuais, atenção visual, movimento dos olhos, percepção e associação das cores, influências culturais e modelos computacionais de atenção visual (atenção visual bottom-up e atenção visual top-down).

No que tange aos artigos teórico-empíricos analisados, a Tabela 1 apresenta os nomes dos seus respectivos autores, ano de publicação, tipo de pesquisa, procedimento para a coleta dos dados, variáveis dependentes e variáveis independentes e, principalmente, seus principais resultados. 


\begin{tabular}{|c|c|c|c|c|c|}
\hline Autores (ano) & $\begin{array}{l}\text { Tipo de Pes- } \\
\text { quisa }\end{array}$ & Coleta de Dados & Variáveis Dependentes & Variáveis Independentes & Principais Resultados \\
\hline $\begin{array}{l}\text { Rosbergen, } \\
\text { Pieters e Wedel } \\
\quad(1997)\end{array}$ & Causal & $\begin{array}{l}\text { Experimento e uso do } \\
\text { Eye-tracking }\end{array}$ & $\begin{array}{l}\text { Recordação e atitude } \\
\text { para com a marca e } \\
\text { anúncio; Atenção visual; } \\
\text { Envolvimento. }\end{array}$ & $\begin{array}{l}\text { Propriedades físicas em anúncios } \\
\text { (título, tamanho, embalagem do } \\
\text { produto, cor, localização). }\end{array}$ & $\begin{array}{l}\text { Investigando os efeitos das propriedades físicas de anúncios na } \\
\text { atenção visual, identificou-se três segmentos de consumidores } \\
\text { - digitalização, atenção inicial e atenção sustentada - apresen- } \\
\text { tando padrões distintos de atenção visual, envolvimento com } \\
\text { o produto, atitude para com a marca e recordação publicitária. }\end{array}$ \\
\hline $\begin{array}{l}\text { Spies, Hesse e } \\
\text { Loesch (1997) }\end{array}$ & Causal & Experimento & $\begin{array}{l}\text { Estado de Humor; Satis- } \\
\text { fação; Comportamento } \\
\text { de Compra. }\end{array}$ & $\begin{array}{l}\text { Loja A (moderna e layout estru- } \\
\text { turado). vs. Loja B (deteriorada e } \\
\text { layout mal estruturado). }\end{array}$ & $\begin{array}{l}\text { Identificou-se que o estado de humor dos consumidores me- } \\
\text { Ihorou na atmosfera de loja agradável, mas deteriorou-se com } \\
\text { a menos agradável. A atmosfera da loja não afetou a quantida- } \\
\text { de total de dinheiro gasto, mas gastou-se a mais em compras } \\
\text { espontâneas. }\end{array}$ \\
\hline $\begin{array}{c}\text { Raghubir e } \\
\text { Krishna (1999) }\end{array}$ & Causal & Experimento & $\begin{array}{l}\text { Percepção de volume } \\
\text { e Consumo real; Es- } \\
\text { colha; Satisfação no } \\
\text { pós-consumo. }\end{array}$ & $\begin{array}{l}\text { Taça vs. copo redondo; Recipiente } \\
\text { raso vs. alto. }\end{array}$ & $\begin{array}{l}\text { Examinando as expectativas com base em inputs perceptuais } \\
\text { contra experiências sensoriais no contexto de percepções de } \\
\text { volume, contatou-se que a forma do recipiente afeta a prefe- } \\
\text { rência, escolha e satisfação pós-consumo do consumidor. }\end{array}$ \\
\hline $\begin{array}{l}\text { Pieters e War- } \\
\text { lop (1999) }\end{array}$ & Causal & $\begin{array}{c}\text { Experimento e } \\
\text { Eye-movement data }\end{array}$ & $\begin{array}{l}\text { Atenção visual; Me- } \\
\text { mória; Capacidade de } \\
\text { processamento. }\end{array}$ & $\begin{array}{l}\text { Pressão do tempo (baixo vs. alto); } \\
\text { Motivação de tarefa (baixa condi- } \\
\text { ção vs. alta condição). }\end{array}$ & $\begin{array}{l}\text { A atenção visual dos consumidores se adapta rapidamente às } \\
\text { diferenças de pressão de tempo e motivação de tarefa durante } \\
\text { a escolha das marcas, acelerando a sequência de exploração } \\
\text { visual, filtrando as informações e mudando a estratégia de di- } \\
\text { gitalização. }\end{array}$ \\
\hline $\begin{array}{l}\text { Fiore, Yah e Yoh } \\
\quad(2000)\end{array}$ & Causal & Experimento & $\begin{array}{l}\text { Atitude; Intenção } \\
\text { de Compra; Prazer } \\
\text { sensorial, emocional e } \\
\text { cognitivo; Preço dis- } \\
\text { posto a pagar. }\end{array}$ & $\begin{array}{l}\text { Fragrância no ambiente (ade- } \\
\text { quada vs. inadequada); } \\
\text { Exibição do Produto (display vs. } \\
\text { sem display); Display (com vs. sem } \\
\text { fragrância). }\end{array}$ & $\begin{array}{l}\text { Os resultados demostram que a adição de uma fragrância } \\
\text { agradável e apropriada para a exibição dos produtos resultou } \\
\text { em aumentos significativos nos níveis de atitude e intenção } \\
\text { de compra para o produto e preços que os sujeitos estavam } \\
\text { dispostos a pagar. }\end{array}$ \\
\hline $\begin{array}{l}\text { Wedel e Pieters } \\
\qquad(2000)\end{array}$ & Descritiva & $\begin{array}{l}\text { Observação com o Eye- } \\
\text { tracking. }\end{array}$ & $\begin{array}{l}\text { Atenção Visual; Memó- } \\
\text { ria das Marcas. }\end{array}$ & $\begin{array}{l}\text { Avaliação de } 65 \text { diferentes anún- } \\
\text { cios contendo (marca vs. imagem } \\
\text { vs. texto). }\end{array}$ & $\begin{array}{l}\text { Verificou-se que o elemento de marca no anúncio captura } \\
\text { uma grande quantidade de atenção, quanto mais informações } \\
\text { são extraídas de um anúncio, menor a latência de memória } \\
\text { da marca. }\end{array}$ \\
\hline $\begin{array}{l}\text { Summers e } \\
\text { Hebert } \\
\text { (2001) }\end{array}$ & Descritiva & Técnicas de observação & $\begin{array}{l}\text { O nível de luz no com- } \\
\text { portamento de aproxi- } \\
\text { mação e evitação. }\end{array}$ & & $\begin{array}{l}\text { Os resultados indicam que os níveis de luz contribuem para o } \\
\text { comportamento de abordagem. A correta iluminação em dis- } \\
\text { plays de exibição pode alcançar um aumento no envolvimento } \\
\text { geral do consumidor com a mercadoria em exposição na loja. }\end{array}$ \\
\hline $\begin{array}{l}\text { Underwood, } \\
\text { Klein e Burke } \\
\quad(2001)\end{array}$ & Causal & Experimento & $\begin{array}{l}\text { Familiaridade; Atenção } \\
\text { e Escolha da marca; } \\
\text { Benefício experiencial. }\end{array}$ & $\begin{array}{l}\text { Familiaridade (marca nacional vs. } \\
\text { marca própria); Preços e imagens } \\
\text { das embalagens; Produto. }\end{array}$ & $\begin{array}{l}\text { As imagens na embalagem são dependentes da categoria do } \\
\text { produto, mostrando-se mais benéficas para aqueles com altos } \\
\text { níveis de benefícios experienciais, como doces. Elas trazem } \\
\text { uma maior atenção para as marcas próprias de baixa familia- } \\
\text { ridade. }\end{array}$ \\
\hline $\begin{array}{c}\text { McCabe e } \\
\text { Nowlis (2003) }\end{array}$ & Causal & Experimento & $\begin{array}{l}\text { Percepções de toque; } \\
\text { Probabilidade de Com- } \\
\text { pra. }\end{array}$ & $\begin{array}{l}\text { Informações do objeto; } \\
\text { Tipo de produto (propriedades } \\
\text { materiais vs. geométricas). }\end{array}$ & $\begin{array}{l}\text { Analisando como os consumidores tomam decisões na loja e } \\
\text { ambientes remotos identificou-se uma maior propensão a pe- } \\
\text { gar e tocar produtos com propriedades materiais agradáveis } \\
\text { do que com propriedades geométricas. }\end{array}$ \\
\hline $\begin{array}{l}\text { Pieters e Wedel } \\
\quad(2004)\end{array}$ & Descritiva & $\begin{array}{l}\text { Observação com o Eye- } \\
\text { tracking. }\end{array}$ & $\begin{array}{l}\text { Atenção Visual; } \\
\text { Envolvimento com o } \\
\text { produto; Motivação e } \\
\text { familiaridade com a } \\
\text { marca. }\end{array}$ & $\begin{array}{l}1363 \text { anúncios impressos de } \\
\text { tamanhos diferentes (marca vs. } \\
\text { imagem vs. texto). }\end{array}$ & $\begin{array}{l}\text { O elemento texto no anúncio capta melhor a atenção em pro- } \\
\text { porção direta ao seu tamanho superfície. O elemento marca } \\
\text { transfere de forma mais eficaz a atenção para os outros ele- } \\
\text { mentos. Apenas o elemento texto produz um ganho líquido na } \\
\text { atenção à publicidade como um todo. }\end{array}$ \\
\hline
\end{tabular}

Tabela 1. Artigos Teórico-Empírico selecionados

Fonte: Dados da Pesquisa 


\begin{tabular}{|c|c|c|c|c|c|c|}
\hline Autores (ano) & $\begin{array}{l}\text { Tipo de Pes- } \\
\text { quisa }\end{array}$ & Coleta de Dados & Variáveis Dependentes & Variáveis Independentes & Principais Resultados & \\
\hline $\begin{array}{l}\text { Tang, Fryxell e } \\
\text { Chow (2004) }\end{array}$ & Causal & Experimento & $\begin{array}{l}\text { Quantia de dinheiro } \\
\text { gasto com as quatro } \\
\text { categorias de produtos. }\end{array}$ & $\begin{array}{l}\text { Tipos de produtos contendo três } \\
\text { diferentes marcas; Rótulos Eco- } \\
\text { lógicos. }\end{array}$ & $\begin{array}{l}\text { Com apoio de uma experiência de compra simulada na internet, verificou- } \\
\text { se que os rótulos ecológicos mais eficazes foram aqueles que possuíam o } \\
\text { "selo" e uma "mensagem escrita" adicional que indicava o atributo primá- } \\
\text { rio ambiental do produto. }\end{array}$ & \\
\hline $\begin{array}{l}\text { Sojka e Giese } \\
\quad(2006)\end{array}$ & Causal & Experimento & $\begin{array}{l}\text { Atitude para com o } \\
\text { anúncio e a marca; Afeto } \\
\text { e Cognição. }\end{array}$ & $\begin{array}{l}\text { Anúncios de um produto (somen- } \\
\text { te visual vs. somente verbal vs. } \\
\text { verbal e visual). }\end{array}$ & $\begin{array}{l}\text { Indivíduos com alto afeto respondem mais favoravelmente a anúncios com } \\
\text { elementos visuais. E, indivíduos ricos em afeto e cognição preferem anún- } \\
\text { cios que contêm elementos visuais e verbais. }\end{array}$ & \\
\hline $\begin{array}{l}\text { Chebat e } \\
\text { Morrin (2007) }\end{array}$ & Exploratória & Estudo de Campo & $\begin{array}{l}\text { Percepção de qualida- } \\
\text { de e Humor. }\end{array}$ & & $\begin{array}{l}\text { As percepções dos consumidores quanto à qualidade do produto e ambien- } \\
\text { tal de um shopping são afetadas pelos regimes de decoração. Os Franco- } \\
\text { canadenses foram mais afetados por cores quentes, enquanto os Anglo- } \\
\text { canadenses por cores frias. }\end{array}$ & \\
\hline Clement (2007) & Causal & Experimento & $\begin{array}{l}\text { Atenção visual; } \\
\text { Decisão de compra. }\end{array}$ & $\begin{array}{l}\text { Estímulos visuais (alto vs. baixo } \\
\text { nível) }\end{array}$ & $\begin{array}{l}\text { O estudo revela que os consumidores apresentam uma confusa estratégia } \\
\text { de busca em que o design da embalagem do produto influencia o processo } \\
\text { de decisão em várias fases. }\end{array}$ & \\
\hline $\begin{array}{l}\text { Brasel e Gips } \\
\text { (2008) }\end{array}$ & Causal & $\begin{array}{l}\text { Experimento e uso do } \\
\text { Eye-tracking }\end{array}$ & $\begin{array}{l}\text { Atenção Visual; Atitude } \\
\text { em relação à marca; } \\
\text { Intenção comporta- } \\
\text { mental. }\end{array}$ & $\begin{array}{l}\text { Fast-Forwarding vs. com Regu- } \\
\text { lar-Speed; Logotipo da marca em } \\
\text { nível limitado vs. periférico vs. } \\
\text { centro. }\end{array}$ & $\begin{array}{l}\text { Os comerciantes podem neutralizar os efeitos negativos dos gravadores de } \\
\text { vídeo digital ao garantirem que os seus comerciais apresentem a marca em } \\
\text { uma localização central. }\end{array}$ & \\
\hline $\begin{array}{l}\text { Kim e Lennon } \\
\text { (2008) }\end{array}$ & Causal & Experimento & $\begin{array}{l}\text { Respostas afetivas, } \\
\text { atitudinais e cognitivas; } \\
\text { Intenção de compra na } \\
\text { internet. }\end{array}$ & $\begin{array}{l}\text { Apresentação do produto visual } \\
\text { (fotos, tamanho) vs. verbal (tex- } \\
\text { tos, quantidade de informação). }\end{array}$ & $\begin{array}{l}\text { Tanto as informações visuais quanto as verbais possuem efeitos nas atitu- } \\
\text { des afetivas e cognitivas dos consumidores. Mas, as informações verbais } \\
\text { tiveram um efeito significativo sobre a intenção de compra, demonstrando } \\
\text { uma superioridade na apresentação do produto na Internet. }\end{array}$ & \\
\hline $\begin{array}{l}\text { Stoll, Baecke, e } \\
\text { Kenning (2008) }\end{array}$ & Causal & $\begin{array}{l}\text { Experimento e uso de } \\
\text { fMRI }\end{array}$ & $\begin{array}{l}\text { Atitude em relação à } \\
\text { embalagem do produto; } \\
\text { Atração Visual. }\end{array}$ & $\begin{array}{l}\text { Embalagens de produtos } \\
\text { (atraentes vs. desinteressantes). }\end{array}$ & $\begin{array}{l}\text { Embalagens atraentes e pouco atraentes são capazes de desencadear dife- } \\
\text { rentes alterações na atividade cortical. Embalagens mais atraentes ganham } \\
\text { mais atenção no ponto-de-venda influenciando na rotatividade de bens de } \\
\text { consumo rápido. }\end{array}$ & \\
\hline $\begin{array}{l}\text { Chandon et. al. } \\
\qquad(2009)\end{array}$ & Causal & $\begin{array}{l}\text { Experimento e uso do } \\
\text { Eye-tracking }\end{array}$ & $\begin{array}{l}\text { Atenção Visual; } \\
\text { Avaliação das marcas. }\end{array}$ & $\begin{array}{l}\text { Fatores in-store vs. } \\
\text { fatores out-of-store. }\end{array}$ & $\begin{array}{l}\text { Os fatores out-of-store (mercado da marca, demografia do consumidor) } \\
\text { influenciam diretamente a avaliação da marca e não são mediados pela } \\
\text { atenção, já os fatores in-store (número e a posição dos revestimentos na } \\
\text { prateleira) influenciam a atenção e, por essa via, a avaliação das marcas. }\end{array}$ & \\
\hline $\begin{array}{c}\text { Valenzuela e } \\
\text { Raghubir (2009) }\end{array}$ & Causal & Experimento & $\begin{array}{l}\text { Atenção; Intenções de } \\
\text { compra; Índice de po- } \\
\text { pularidade; Escolha do } \\
\text { produto. }\end{array}$ & $\begin{array}{l}\text { Posições de apresentação dos } \\
\text { produtos (extrema-esquerda, } \\
\text { esquerda, médio, direita vs. extre- } \\
\text { ma-direita). }\end{array}$ & $\begin{array}{l}\text { Os resultados indicam que um produto em uma posição central é preferível } \\
\text { a outro localizado na extremidade da matriz, em razão das crenças que os } \\
\text { consumidores possuem de que estes são mais populares e não devido a } \\
\text { uma maior atenção dada ao produto. }\end{array}$ & \\
\hline $\begin{array}{l}\text { Zhang, Wedel, e } \\
\text { Pieters (2009) }\end{array}$ & Descritiva & $\begin{array}{l}\text { Observação com o } \\
\text { Eye-tracking. }\end{array}$ & $\begin{array}{l}\text { Atenção Visual; Impacto } \\
\text { nas vendas. }\end{array}$ & $\begin{array}{l}\text { Tamanho do anúncio, cores, locali- } \\
\text { zação; Página de exibição; Vendas } \\
\text { semanais. }\end{array}$ & $\begin{array}{l}\text { Identificou-se que a atenção nos anúncios não só afeta as vendas, mas } \\
\text { também representa um mediador dos efeitos de várias características de } \\
\text { design dos anúncios sobre as vendas. }\end{array}$ & $\begin{array}{l}\text { Tabela } 1 . \\
\text { Continuação } \\
\text { Fonte: Dados da } \\
\text { Pesquisa }\end{array}$ \\
\hline
\end{tabular}




\begin{tabular}{|c|c|c|c|c|c|}
\hline Autores (ano) & $\begin{array}{l}\text { Tipo de Pes- } \\
\text { quisa }\end{array}$ & Coleta de Dados & Variáveis Dependentes & Variáveis Independentes & Principais Resultados \\
\hline $\begin{array}{l}\text { Creusen, Very- } \\
\quad \text { zer e } \\
\text { Schoormans } \\
\quad(2010)\end{array}$ & Causal & Experimento & $\begin{array}{l}\text { Preferências por com- } \\
\text { plexibilidade e simetria } \\
\text { no produto. }\end{array}$ & $\begin{array}{l}\text { Tipo de valor do produto quanto } \\
\text { a: Estética, funções, } \\
\text { qualidade, fácil utilização. }\end{array}$ & $\begin{array}{l}\text { A quantidade de complexidade visual influencia na percepção dos tipos de } \\
\text { valor do produto, ou seja, a estética, funcionalidades, qualidade e facilida- } \\
\text { de de utilização. }\end{array}$ \\
\hline $\begin{array}{l}\text { Goodrich } \\
(2010)\end{array}$ & Causal & Experimento & $\begin{array}{l}\text { Atenção; Atitude de } \\
\text { marca; Evocação auxilia- } \\
\text { da (Aided recall). }\end{array}$ & $\begin{array}{l}\text { Formato do anúncio (retângulo vs. } \\
\text { leaderboard). }\end{array}$ & $\begin{array}{l}\text { O formato de anúncio online (anúncio retângulo ou leaderboard) demons- } \\
\text { tra um efeito na atenção, evocação auxiliada e atitude de marca. Pode-se } \\
\text { melhorar a atenção dos clientes e evocação auxiliada ao colocar anúncios } \\
\text { mais baixos no campo visual e usando formatos incomuns. }\end{array}$ \\
\hline $\begin{array}{l}\text { Pieters, Wedel e } \\
\text { Batra (2010) }\end{array}$ & Causal & $\begin{array}{l}\text { Experimento e uso do } \\
\text { Eye-tracking }\end{array}$ & $\begin{array}{l}\text { Atenção visual; Atitude } \\
\text { em relação ao anúncio. }\end{array}$ & $\begin{array}{l}249 \text { anúncios de revistas (desde } \\
\text { anúncios simples a muito com- } \\
\text { plexos). }\end{array}$ & $\begin{array}{l}\text { Há dois tipos distintos de complexidade visual. A complexidade caracterís- } \\
\text { tica tem um efeito negativo sobre a atenção da marca e atitude para com } \\
\text { o anúncio, já a complexidade do projeto tem um efeito positivo sobre a } \\
\text { atenção e atitude em relação ao anúncio. }\end{array}$ \\
\hline $\begin{array}{l}\text { Reimann et. al. } \\
\text { (2010) }\end{array}$ & Causal & $\begin{array}{l}\text { Experimento e uso de } \\
\text { Fmri }\end{array}$ & $\begin{array}{l}\text { Escolha da marca e do } \\
\text { produto; Tempo de } \\
\text { reação. }\end{array}$ & $\begin{array}{l}\text { Embalagem estética (marca } \\
\text { conhecida vs. desconhecida) vs. } \\
\text { embalagem padronizada (marca } \\
\text { conhecida vs. desconhecida). }\end{array}$ & $\begin{array}{l}\text { Leva-se mais tempo para escolher produtos com embalagens estéticas do } \\
\text { que padronizadas. As marcas desconhecidas com embalagens estéticas } \\
\text { foram escolhidas com maior frequência que marcas conhecidas. Achados } \\
\text { são resultantes do aumento da ativação do sistema de recompensa dos } \\
\text { indivíduos. }\end{array}$ \\
\hline $\begin{array}{l}\text { Hoegg e Alba } \\
\quad \text { (2011) }\end{array}$ & Causal & Experimento & $\begin{array}{l}\text { Atenção e Julgamento } \\
\text { dos recursos funcionais. }\end{array}$ & $\begin{array}{l}\text { Produto com desempenho funcio- } \\
\text { nal superior vs. com desempenho } \\
\text { funcional inferior. }\end{array}$ & $\begin{array}{l}\text { A forma de um produto sugere um determinado nível de desempenho fun- } \\
\text { cional, os consumidores naturalmente incorporam essa informação para os } \\
\text { julgamentos do produto. Percebeu-se que influência da forma de produto } \\
\text { sobre o consumidor é independente de apelo estético. }\end{array}$ \\
\hline $\begin{array}{l}\text { Hsieh e Chen } \\
\quad \text { (2011) }\end{array}$ & Causal & Experimento & $\begin{array}{l}\text { Atenção; Intensidade de } \\
\text { recordação. }\end{array}$ & $\begin{array}{l}\text { Informação do conteúdo de na- } \\
\text { vegação em uma página de web } \\
\text { (texto; mistos com texto-imagem; } \\
\text { em imagem vs. em vídeo). }\end{array}$ & $\begin{array}{l}\text { Analisando a forma e a estrutura de informação das variadas páginas da } \\
\text { web percebeu-se que as páginas baseadas em vídeo e imagens são as me- } \\
\text { lhores para o desenho de publicidade e a atenção dos usuários do que as } \\
\text { páginas baseadas em texto e, texto e imagens. }\end{array}$ \\
\hline $\begin{array}{l}\text { Van Rompay e } \\
\text { Pruyn (2011) }\end{array}$ & Causal & Experimento & $\begin{array}{l}\text { Percepções de credi- } \\
\text { bilidade e estética da } \\
\text { marca; } \\
\text { Expectativas de preços. }\end{array}$ & $\begin{array}{l}\text { Formato da garrafa; Tipo de letra } \\
\text { do rótulo; Masculinidade (áspero) } \\
\text { vs. feminilidade (suave). }\end{array}$ & $\begin{array}{l}\text { Observou-se a grande importância de uma congruência entre os significa- } \\
\text { dos simbólicos e as características visuais do produto. A congruência afeta } \\
\text { positivamente o valor percebido do produto. }\end{array}$ \\
\hline $\begin{array}{l}\text { Atalay, Bodur e } \\
\text { Rasolofoarison } \\
\quad(2012)\end{array}$ & Causal & $\begin{array}{l}\text { Experimento e uso do } \\
\text { Eye-tracking }\end{array}$ & $\begin{array}{l}\text { Atenção Visual; } \\
\text { Frequência de escolha } \\
\text { da marca. }\end{array}$ & $\begin{array}{l}\text { Localização da marca (à esquerda, } \\
\text { no centro vs. à direita); Duração } \\
\text { total de fixações do olho em cada } \\
\text { marca. }\end{array}$ & $\begin{array}{l}\text { O estudo realizado com produtos tangíveis demonstrou que o produto } \\
\text { localizado centralmente dentro de uma categoria de produto é escolhido } \\
\text { mais frequentemente, mesmo quando não está colocado no centro do } \\
\text { campo visual. }\end{array}$ \\
\hline $\begin{array}{l}\text { Elder e Krishna } \\
\quad(2012)\end{array}$ & Causal & Experimento & $\begin{array}{l}\text { Intenção de compra; } \\
\text { Atitude; Facilidade e } \\
\text { simulação mental incor- } \\
\text { porada. }\end{array}$ & $\begin{array}{l}\text { Lado direito vs. esquerdo; Simula- } \\
\text { ção de bloqueio; Imagem de uma } \\
\text { caneca (alça do lado esquerdo vs. } \\
\text { direito). }\end{array}$ & $\begin{array}{l}\text { Destaca-se que simplesmente alterando a forma como o produto é visual- } \\
\text { mente representado em um anúncio pode provocar mais (ou menos) si- } \\
\text { mulação mental de interação com o produto e que isso pode resultar em } \\
\text { maiores (ou menores) intenções de compra. }\end{array}$ \\
\hline
\end{tabular}

Tabela 1.

Continuação

Fonte:

Dados da

Pesquisa 
Tabela 1. Continuação

\begin{tabular}{|c|c|c|c|c|c|}
\hline Autores (ano) & $\begin{array}{l}\text { Tipo de Pes- } \\
\text { quisa }\end{array}$ & Coleta de Dados & Variáveis Dependentes & Variáveis Independentes & Principais Resultados \\
\hline $\begin{array}{c}\text { Chae e Lee } \\
\text { (2013) }\end{array}$ & Causal & $\begin{array}{l}\text { Experimento e uso do } \\
\text { Eye-tracking }\end{array}$ & $\begin{array}{l}\text { Qualidade de decisão; } \\
\text { Atenção visual; Con- } \\
\text { fiança percebida do } \\
\text { produto. }\end{array}$ & $\begin{array}{l}\text { Tipo de produto (simbólico vs. } \\
\text { funcional); Anúncios com combi- } \\
\text { nações humanos e produtos. }\end{array}$ & $\begin{array}{l}\text { A marca humana (pessoa conhecida que é objeto de esforços de marketing) } \\
\text { influencia a tomada de decisão dos consumidores, reduzindo o seu esforço } \\
\text { cognitivo, apelando emocionalmente por meio de suas escolhas heurísticas } \\
\text { e amentando a confiança para produtos funcionais e bons pensamentos } \\
\text { sobre as decisões tomadas. }\end{array}$ \\
\hline $\begin{array}{l}\text { Puccinelli et. al. } \\
\text { (2013) }\end{array}$ & Causal & Experimento & $\begin{array}{l}\text { Percepção da econo- } \\
\text { mia; } \\
\text { Estado emocional; } \\
\text { Recordação; Reconheci- } \\
\text { mento de informações. }\end{array}$ & $\begin{array}{l}\text { Cor do preço (vermelho vs. } \\
\text { preto); Estado de envolvimento } \\
\text { (alto vs. baixo); Sexo do parti- } \\
\text { cipante. }\end{array}$ & $\begin{array}{l}\text { Os homens respondem mais positivamente à cor vermelha em condições } \\
\text { de baixo envolvimento. Esses efeitos se estendem a percepção da infor- } \\
\text { mação de preços em um anúncio, quando aparecem em vermelho, eles } \\
\text { percebem uma maior poupança. Já as mulheres mostram-se imunes aos } \\
\text { efeitos da cor vermelha, devido à sua tendência em processar anúncios } \\
\text { com maior profundidade. }\end{array}$ \\
\hline $\begin{array}{c}\text { Otterbring, Lof- } \\
\text { gren e Lestelius } \\
\text { (2014) }\end{array}$ & Causal & Experimento & $\begin{array}{l}\text { Percepções de preços; } \\
\text { Inferências de quali- } \\
\text { dade; Gosto inferido; } \\
\text { Atratividade. }\end{array}$ & $\begin{array}{l}\text { Produtos embalados acondiciona- } \\
\text { dos sob: luz fria (LED azul) vs. luz } \\
\text { morna (LED amarelo). }\end{array}$ & $\begin{array}{l}\text { Investigou-se como iluminação pode vir a influenciar as avaliações dos } \\
\text { consumidores sobre produtos alimentares embalados. Os resultados de- } \\
\text { mostram independentemente da embalagem, os produtos alimentares fo- } \\
\text { ram avaliados mais negativamente sob a luz fria do que em luz morna. Os } \\
\text { produtos em luz fria foram julgados como inferiores em qualidade, menos } \\
\text { atraentes e menos apetitosos. }\end{array}$ \\
\hline $\begin{array}{l}\text { Otterbring et. } \\
\text { al. (2014) }\end{array}$ & Causal & $\begin{array}{l}\text { Experimento com } \\
\text { uso do Eye-tracking }\end{array}$ & $\begin{array}{l}\text { Atenção Visual; } \\
\text { Escolha do produto. }\end{array}$ & $\begin{array}{l}\text { Fixações dos olhos para os } \\
\text { sinais de apresentação na } \\
\text { loja; Familiaridade vs. loja } \\
\text { desconhecida; Navegação na } \\
\text { loja vs. tomada de decisão. }\end{array}$ & $\begin{array}{l}\text { A sinalização no interior da loja, quando percebida, tem um gran- } \\
\text { de impacto sobre onde o cliente irá dirigir a sua atenção visual. } \\
\text { Esta atenção irá variar em função da familiaridade dos clientes } \\
\text { com a loja e do estágio específico do processo de pesquisa. No } \\
\text { entanto, nem sempre é suficiente simplesmente fornecer infor- } \\
\text { mações específicas do produto a ser exibido. }\end{array}$ \\
\hline $\begin{array}{l}\text { Clement, } \\
\text { Aastrup e } \\
\text { Forsberg } \\
\text { (2015) }\end{array}$ & Causal & $\begin{array}{c}\text { Experimento com } \\
\text { uso do Eye-tracking } \\
\text { e Dados de Vendas } \\
\text { Reais }\end{array}$ & $\begin{array}{l}\text { Atenção visual; Ven- } \\
\text { das reais no super- } \\
\text { mercado. }\end{array}$ & $\begin{array}{l}\text { Marcas (nacionais muito e } \\
\text { pouco conhecidas vs. marcas } \\
\text { próprias); Disposição dos } \\
\text { produtos. }\end{array}$ & $\begin{array}{l}\text { Analisando as táticas no ponto de venda, verificou-se que quan- } \\
\text { do colocadas próximas, tanto a marca própria quanto da marca } \\
\text { nacional, demostram um aumento positivo em seus volumes de } \\
\text { vendas. As marcas próprias parecem, em geral, beneficiarem-se } \\
\text { do posicionamento e uso de sinalização quanto a uma marca na- } \\
\text { cional fraca. }\end{array}$ \\
\hline $\begin{array}{l}\text { Huddleston } \\
\text { et. al. (2015) }\end{array}$ & Causal & $\begin{array}{l}\text { Experimento com } \\
\text { uso do Eye-tracking }\end{array}$ & $\begin{array}{l}\text { Atenção visual; } \\
\text { Intenção de compra; } \\
\text { Tempo de visita. }\end{array}$ & $\begin{array}{l}\text { Display com informação do } \\
\text { produto (sem o preço) vs. Dis- } \\
\text { play com apenas o preço (sem } \\
\text { informação produto). }\end{array}$ & $\begin{array}{l}\text { Verificou-se que as informações do produto em uma placa e a au- } \\
\text { sência de preços para produtos minimamente embalados, como } \\
\text { flores, mostrou-se mais influente na motivação e probabilidade } \\
\text { para comprar. Este achado sugere que o preço deve ser uma men- } \\
\text { sagem secundária as informações sobre o produto no ponto-de- } \\
\text { venda. }\end{array}$ \\
\hline
\end{tabular}

Fonte: Dados

da Pesquisa 
Tabela 1. Continuação

\begin{tabular}{|c|c|c|c|c|c|}
\hline Autores (ano) & $\begin{array}{l}\text { Tipo de Pes- } \\
\text { quisa }\end{array}$ & Coleta de Dados & Variáveis Dependentes & Variáveis Independentes & Principais Resultados \\
\hline $\begin{array}{l}\text { Petroll e Pra- } \\
\text { do (2015) }\end{array}$ & $\begin{array}{c}\text { Explorató-ria } \\
\text { Causal }\end{array}$ & $\begin{array}{l}\text { Grupo focal, } \\
\text { Experimento e uso } \\
\text { do Eye-tracking }\end{array}$ & $\begin{array}{l}\text { Atenção visual; Me- } \\
\text { mória e atitude sobre } \\
\text { a marca; Intenção de } \\
\text { compra. }\end{array}$ & $\begin{array}{l}\text { Pop-up ad (alta vs. baixa proe- } \\
\text { minência); Estímulos (con- } \\
\text { gruentes vs. incongruentes). }\end{array}$ & $\begin{array}{l}\text { Verificou-se os efeitos da prominência e da congruência do place- } \\
\text { ment e do tipo pop-up ad sobre a atenção visual, memória, atitu- } \\
\text { des e intenção de compra da marca pelo consumidor. Identificou- } \\
\text { se que a proeminência afeta significativamente a atenção visual } \\
\text { do consumidor, mas não há efeitos significativos para os demais } \\
\text { construtos. }\end{array}$ \\
\hline $\begin{array}{l}\text { Storme et. al. } \\
\text { (2015) }\end{array}$ & Causal & Experimento & $\begin{array}{l}\text { Processamento de } \\
\text { fluência; Atenção; } \\
\text { Intenção de Compra; } \\
\text { Atitude para com a } \\
\text { marca. }\end{array}$ & $\begin{array}{l}\text { Três anúncios diferentes } \\
\text { produtos (bebida, bicicleta } \\
\text { vs. carro). }\end{array}$ & $\begin{array}{l}\text { O estudo destaca como processamento de fluência afeta as atitu- } \\
\text { des e intenções de compra. Identificou-se que é possível aumen- } \\
\text { tar atitudes positivas para com o anúncio e objetos relacionados. } \\
\text { Na verdade, propagandas que obtém um processamento mais } \\
\text { cognitivo provocam atitudes mais positivas em relação ao anún- } \\
\text { cio, marca e intenção de compra. }\end{array}$ \\
\hline
\end{tabular}

Constatou-se que, para a realização dos estudos supramencionados, pesquisadores investigaram uma série de estímulos visuais com o intuito de entender de que forma estes poderiam influenciar os mais variados comportamentos do consumidor. Em sua totalidade, os estímulos analisados nos estudos teórico-empíricos estavam relacionados aos principais temas: produtos (27\%), anúncios (24,3\%), atmosfera de lojas físicas (18,9\%), embalagens de produtos $(8,1 \%)$, marcas $(8,1 \%)$, comerciais $(2,7 \%)$, cores $(2,7 \%)$, páginas da web (2,7\%), placement $(2,7 \%)$ e rótulos ecológicos $(2,7 \%)$.

No tocante aos produtos, abordou-se, por exemplo, sobre as percepções dos consumidores quanto ao volume e ao design dos produtos (RAGHUBIR; KRISHNA, 1999; CREUSEN; VERYZER; SCHOORMANS, 2010; HOEGG; ALBA, 2011), apresentação destes em locais para compras pela Internet e anúncios (KIM; LENNON, 2008; ELDER; KRISHNA, 2012), relevância da congruência entre os significados simbólicos e as suas características visuais (VAN ROMPAY; PRUYN, 2011) e a adequada exposição nos pontos de venda (VALENZUELA; RAGHUBIR, 2009; ATALAY; BODUR; RASOLOFOARISON, 2012; HUDDLESTON et al., 2015).

Outros estudos examinados se esforçaram em analisar de que forma os elementos do anúncio - marcas, imagens e texto - impactam no comportamento do consumidor (WEDEL; PIETERS, 2000; WEDEL; PIETERS, 2004; ZHANG; WEDEL; PIETERS, 2009). Além disso, Sojka e Giese (2006) constataram que o nível de afeto do indivíduo apresenta influência direta sobre suas respostas perante o anúncio; Goodrich (2010) demostrou que o seu posi- 
cionamento na publicidade online tem impactos diferentes na atenção e, ainda, identificou-se que anúncios que requerem um maior processamento cognitivo do consumidor provocam atitudes mais positivas sobre o próprio anúncio, a marca do produto ou serviço e a sua intenção de compra (STORME et. al.,2015).

Outros estudos analisados procuraram investigar, por exemplo, os efeitos da atmosfera da loja sobre a satisfação, o comportamento de compra e as percepções com relação à qualidade do produto (SPIES; HESSE; LOESCH, 1997; CHEBAT; MORRIN, 2007); a influência das fragrâncias na exibição dos produtos (FIORE; YAH; YOH, 2000); a adequada iluminação dos displays de exibição (SUMMERS; HEBERT, 2001; OTTERBRING; LOFGREN; LESTELIUS, 2014); e o impacto da sinalização no interior da loja sobre a atenção visual do consumidor (OTTERBRING et al., 2014).

Com relação ao consumidor, foram investigados: a atenção visual, a recordação, a memória, a motivação, as atitudes, o afeto, as expectativas, os estados de humor, a satisfação, as intenções de compra, as percepções, as escolhas, o envolvimento, o consumo real e percebido, a capacidade de processamento, a familiaridade, a disposição a pagar e o prazer sensorial, cognitivo e emocional.

Para tanto, os 37 estudos aqui levantados abarcaram, principalmente, pesquisas do tipo causal (83,8\%), a partir de experimentos, alguns destes (42\% do total de artigos do tipo causal) auxiliados por tecnologias como o Eye tracking, na área de marketing e também na da psicologia cognitiva e comportamental (UNDERWOOD; KLEIN; BURKE, 2001). Todavia, há de se ter ressalvas quanto aos resultados encontrados por estudos que utilizaram o Eye tracking, pois, segundo Hsieh e Chen (2011), muitos pesquisadores não são qualificados para o uso dessa tecnologia, restringindo-se em solicitar aos participantes que simplesmente olhem para determinado estímulo em experimentos em laboratório ao invés de colocá-los em uma situação real ou o mais próximo possível do mundo real a partir de experimentos de campo ou até mesmo em laboratório.

\section{CONSIDERAÇÕES FINAIS}

Almejando uma melhor comunicação e manutenção dos relacionamentos com os seus clientes, as organizações utilizam o marketing 
visual como uma importante estratégia mercadológica. Faz-se necessário, portanto, monitorar os estímulos aos quais consumidores prestam atenção (WEDEL; PIETERS, 2006). Nesse sentido, o marketing visual tem por objetivo fundamental entender e avaliar como as atividades e estímulos visuais podem influenciar os consumidores (WEDEL; PIETERS, 2008).

Ao perceber a relevância do marketing visual para as organizações, o presente trabalho buscou levantar os estudos publicados nos últimos vinte anos (1995-2015), tanto nacionais quanto internacionais. Para tanto, foi realizado uma revisão sistemática nas bases de dados Web of Science, EBSCO, Spell e Scopus, respeitando alguns critérios pré-determinados. Ao término das pesquisas uma amostra de 42 artigos publicados foi composta, divididos entre ensaios teóricos (5 artigos) e teórico-empíricos (37 artigos).

No decorrer das análises foi facilmente percebida uma grande carência de estudos nacionais na área, apenas um artigo publicado em 2015, realidade provavelmente semelhante no que se refere à pesquisa de cunho gerencial no país. Todavia, no âmbito internacional identificou-se um crescimento das publicações referentes ao tema, por exemplo, de 1995 até o ano de 2005 somaram-se 12 artigos, enquanto entre 2006 e 2015 foram encontrados 29 artigos.

Outro aspecto que reforça o crescente interesse da comunidade científica pelo marketing visual é verificado quanto às revistas em que foram publicados os artigos selecionados. Identificou-se 26 diferentes periódicos, demonstrando certa pulverização. Entre os periódicos mais recorrentes estão: Journal of Marketing (5 artigos), Psychology \& Marketing (4 artigos), Journal of Consumer Research (4 artigos) e Journal of Consumer Psychology (3 artigos).

Ainda, com relação à amostra selecionada ocorreu uma forte predominância de estudos causais que utilizavam experimentos para coleta e dados, em alguns casos, apoiados com o uso de tecnologias como o Eye-tracking e a Ressonância Magnética Funcional (fMRI). Os artigos abordaram diferentes aspectos visuais e suas relações com os mais variados comportamentos dos consumidores, além disso, verificou-se que dentre os 37 estudos teórico-empíricos identificados, 70,3\% deles possuíam suas pesquisas direcionadas para melhor compreensão dos produtos (27\%), anúncios (24,3\%) e atmosfera de lojas físicas (18,9\%).

Para os autores, este estudo contribui para uma maior compreensão 
do marketing visual, uma vez que expõe um panorama dos estudos que abordam a temática analisada, bem como seus principais resultados. A amostra selecionada é entendida como um relevante insumo para os demais pesquisadores, grupos de pesquisas, gestores e interessados. Ademais, após uma análise detalhada dos artigos supracitados, chegou-se à definição de três importantes caminhos a serem seguidos no âmbito do marketing visual.

Em primeiro lugar, os proponentes deste trabalho indicam a realização de mais estudos que explorem as mídias digitais, isto porque percebeu-se que apenas 6 estudos abordavam estímulos visuais no contexto da internet, aquém da sua importância, já que estima-se que as mídias digitais manterão a sua ascensão exponencial como canal de investimentos em propaganda, ratificado pelos US\$ 160 bilhões gastos em 2015 e pelas projeções de que até 2017 a mídia digital ultrapasse a TV como a maior categoria para a veiculação de propaganda (EMBER, 2015).

Em segundo lugar, os consumidores são incapazes de assimilar todos os estímulos a qual estão expostos (PIETERS; WEDEL, 2004). Camargo (2013) corrobora ao salientar que os indivíduos vivem, em grande parte do tempo, em uma condição de piloto automático, pois é impossível estarem conscientes de todos os estímulos existentes no ambiente. Isso faz com que o sistema nervoso escolha determinados estímulos e descarte outros. Destarte, a neurociência é uma importante aliada para desvendar os processos que os indivíduos não estão conscientes e, consequentemente, complementar os métodos tradicionais de pesquisa de marketing (POZHARLIEV et al., 2015). No âmbito dos artigos analisados, observou-se que alguns poucos tinham suas investigações apoiadas por tecnologias como a Ressonância Magnética Funcional (fMRI) e o Eye tracking. Assim como indicado pelos pesquisadores Milosavljevic e Cerf (2008), propõem-se a realização de mais estudos que combinem o marketing com a neurociência, bem como o uso das tecnologias supracitadas, levando em consideração a crítica de Hsieh e Chen (2011) quanto à expertise de alguns pesquisadores no uso de tais tecnologias. De todo modo, Camargo (2013) considera que a interdisciplinaridade é um fator fundamental para o entendimento do comportamento humano e especialmente o do consumidor de forma completa e precisa.

Em terceiro lugar, verificou-se que todos os 37 artigos teóricoempíricos averiguaram temas sob o contexto dos meios tradicionais de comunicação de massa como, por exemplo, TV, jornal e internet. Segundo 
Kotler e Keller (2012), a diminuição da eficácia dos meios tradicionais de comunicação de massa tem motivado os anunciantes a aumentar sua ênfase em meios alternativos - outdoors, espaços públicos, pontos de vendas -, contemplando inúmeras maneiras criativas e singulares para atrair maior atenção dos indivíduos. Portanto, o terceiro caminho indicado para trabalhos vindouros consiste em explorações quanto à eficácia dos meios alternativos para a divulgação de estímulos visuais direcionados aos consumidores.

Comolimitações do presente estudo destaca-seo uso de determinadas palavras-chave e de possíveis vieses por parte dos pesquisadores na análise dos artigos levantados a partir da revisão sistemática. Estes dois pontos podem ter contribuído para que certos artigos que exploram o marketing visual não tenham feito parte da amostra selecionada.

Por fim, destaca-se que o estudo sobre marketing visual deve ser estimulado, pois o entendimento do comportamento real do consumidor ainda é incipiente, mas necessário para que se possa conhecê-lo e fortalecer o poder do marketing das organizações (SACHARIN, 2001).

\section{NOTAS}

[1] De acordo com Camargo (2013), a Ressonância Magnética Funcional (fMRI) refere-se a uma técnica em que os participantes da pesquisa são alocados em um equipamento cilíndrico e lhes são mostrados estímulos visuais ou auditivos de marketing como, por exemplo, produtos, marcas, sons, embalagens, cores e etc. A tecnologia fMRI demonstrará as regiões do cérebro ativadas por meio da detecção das mudanças no fluxo sanguíneo e oxigenação consumidos por estas diferentes regiões, quanto mais ativa a região, mais oxigênio e sangue são demandados.

[2] Eye tracking, trata-se de uma tecnologia que permite ao pesquisador analisar a atenção do participante do estudo sobre determinado estímulo a partir do rastreamento da movimentação dos seus olhos, principalmente as fixações dos olhos sobre determinado estímulo (WEDEL; PIETERS, 2000), pois estas são interpretadas como respostas de aquisição de informação (CHAE; LEE, 2013).

\section{BIBLIOGRAFIA}

AGAPITO, Dora; MENDES, Júlio; VALLE, Patrícia. Exploring the 
conceptualization of the sensory dimension of tourist experiences. Journal of Destination Marketing \& Management, v. 2, n. 2, p. 62-73, 2013.

ATALAY, A. Selin; BODUR, H. Onur; RASOLOFOARISON, Dina. Shining in the center: Central gaze cascade effect on product choice. Journal of Consumer Research, v. 39, n. 4, p. 848-866, 2012.

BRASEL, S. Adam; GIPS, James. Breaking through fast-forwarding: Brand information and visual attention. Journal of Marketing, v. 72, n. 6, p. 31-48, 2008.

CAMARGO, Pedro. Neuromarketing: A nova pesquisa de comportamento do consumidor. São Paulo: Atlas, 2013.

CHAE, Seong W; LEE, Kun C. Exploring the effect of the human brand on consumers' decision quality in online shopping: An eye-tracking approach. Online Information Review, v. 37, n. 1, p. 83-100, 2013.

CHANDON, Pierre et. al. Does in-store marketing work? Effects of the number and position of shelf facings on brand attention and evaluation at the point of purchase. Journal of Marketing, v. 73, n. 6, p. 1-17, 2009.

CHEBAT, Jean-Charles; MORRIN, Maureen. Colors and cultures: exploring the effects of mall décor on consumer perceptions. Journal of Business Research, v. 60, n. 3, p. 189-196, 2007.

CLEMENT, Jesper. Visual influence on in-store buying decisions: an eyetrack experiment on the visual influence of packaging design. Journal of marketing management, v. 23, n. 9-10, p. 917-928, 2007.

CLEMENT, Jesper; AASTRUP, Jesper; FORSBERG, Signe Charlotte. Decisive visual saliency and consumers $\mathbb{\text { in}}$-store decisions. Journal of Retailing and Consumer Services, v. 22, p. 187-194, 2015.

CREUSEN, Marielle EH; VERYZER, Robert W.; SCHOORMANS, Jan PL. Product value importance and consumer preference for visual complexity and symmetry. European Journal of Marketing, v. 44, n. 9/10, p. 1437-1452, 2010.

DAVENPORT, T., \& BECK, J. The Attention Economy: Understanding the New Currency of Business. Harvard Business School Press, 2001.

DYBÅ, Tore; DINGSØYR, Torgeir. Strength of evidence in systematic reviews in software engineering. In: Proceedings of the Second ACM-IEEE international symposium on Empirical software engineering and measurement. ACM, 2008. p. 178-187.

ELDER, Ryan S.; KRISHNA, Aradhna. The "visual depiction effect" in advertising: Facilitating embodied mental simulation through product orientation. Journal of Consumer Research, v. 38, n. 6, p. 988-1003, 2012. 
eMARKETER (2015, Setembro). Total Media Ad Spending Growth Slows Worldwide. eMarketer. Disponível em: <http://www.emarketer.com/Article/ Total-Media-Ad-Spending-Growth-Slows-Worldwide/1012981>. Acesso em: 16 fev. 2016

EMBER, S. (2015, Dezembro). Digital Ad Spending Expected to Soon Surpass TV. The New York Times. Disponível em: <http://www.nytimes. com/2015/12/07/business/media/digital-ad-spending-expected-to-soonsurpass-tv.html?_r=0>. Acesso em: 16 fev. 2016

FIORE, Ann Marie; YAH, Xinlu; YOH, Eunah. Effects of a product display and environmental fragrancing on approach responses and pleasurable experiences. Psychology and Marketing, v. 17, n. 1, p. 27-54, 2000.

GOODRICH, Kendall. What's Up?. Journal of Advertising Research, v. 50, n. 1, p. 91-106, 2010.

GROSSMAN, P. Randi; WISENBLIT, Joseph Z. What we know about consumers' color choices. Journal of marketing practice: Applied marketing science, v. 5, n. 3, p. 78-88, 1999.

HSIEH, Yu-Chen; CHEN, Kuo-Hsiang. How different information types affect viewer's attention on internet advertising. Computers in Human Behavior, v. 27, n. 2, p. 935-945, 2011.

HOEGG, JoAndrea; ALBA, Joseph W. Seeing is believing (too much): The influence of product form on perceptions of functional performance. Journal of Product Innovation Management, v. 28, n. 3, p. 346-359, 2011.

HUDDLESTON, Patricia et. al. Seeking attention: an eye tracking study of instore merchandise displays. International Journal of Retail \& Distribution Management, v. 43, n. 6, p. 561-574, 2015.

HULTÉN, Bertil. Sensory marketing: the multi-sensory brand-experience concept. European Business Review, v. 23, n. 3, p. 256-273, 2011.

IBOPEMedia (2015b, Setembro). Investimento publicitário semantémestável no $1^{\circ}$ semestre de 2015. Kantar IBOPE Media. Disponível em: <https://www. kantaribopemedia.com/investimento-publicitario-se-mantem-estavel-no10-semestre-de-2015-aponta-ibope-media-2/> Acesso em: 16 fev. 2016

KIM, Minjeong; LENNON, Sharron. The effects of visual and verbal information on attitudes and purchase intentions in internet shopping.Psychology \& Marketing, v. 25, n. 2, p. 146-178, 2008.

KOTLER, Philip; KELLER, Kevin L. Administração de marketing. São Paulo: Pearson, 2012.

KRISHNA, Aradhna. Sensory marketing: Research on the sensuality of 
products. New York: Routledge, 2010.

KRISHNA, Aradhna. An integrative review of sensory marketing: Engaging the senses to affect perception, judgment and behavior. Journal of Consumer Psychology, v. 22, n. 3, p. 332-351, 2012.

KRISHNA, Aradhna; SCHWARZ, Norbert. Sensory marketing, embodiment, and grounded cognition: Implications for consumer behavior. Journal of Consumer Psychology, v. 24, n. 2, 159-168, 2014.

LABRECQUE, Lauren I.; PATRICK, Vanessa M.; MILNE, George R. The marketers' prismatic palette: A review of color research and future directions.Psychology \& Marketing, v. 30, n. 2, p. 187-202, 2013.

LURIE, Nicholas H.; MASON, Charlotte H. Visual representation: Implications for decision making. Journal of Marketing, v. 71, n. 1, p. 160-177, 2007.

MCCABE, Deborah Brown; NOWLIS, Stephen M. The effect of examining actual products or product descriptions on consumer preference. Journal of Consumer Psychology, v. 13, n. 4, p. 431-439, 2003.

MILOSAVLJEVIC, Milica; CERF, Moran. First attention then intention: Insights from computational neuroscience of vision. International Journal of Advertising, v. 27, n. 3, p. 381-398, 2008.

OTTERBRING, Tobias; LÖFGREN, Martin; LESTELIUS, Magnus. Let There be Light! An Initial Exploratory Study of Whether Lighting Influences Consumer Evaluations of Packaged Food Products. Journal of sensory studies, v. 29, n. 4, p. 294-300, 2014.

OTTERBRING, Tobias et. al. Vision (im) possible? The effects of in-store signage on customers' visual attention. Journal of Retailing and Consumer Services, v. 21, n. 5, p. 676-684, 2014.

PETROLL, Martin De La Martinière; PRADO, Paulo Henrique Müller Prado. Os Pop-up Ads estão entre Nós: A Invasão desse Placement Televisivo e seus Efeitos sobre o Consumidor com Auxílio da Tecnologia do Eye Tracking. REMark, v. 14, n. 1, p. 18, 2015.

PIETERS, Rik; ROSBERGEN, Edward; WEDEL, Michel. Visual attention to repeated print advertising: A test of scanpath theory. Journal of Marketing Research, p. 424-438, 1999.

PIETERS, Rik; WARLOP, Luk. Visual attention during brand choice: The impact of time pressure and task motivation. International Journal of Research in Marketing, v. 16, n. 1, p. 1-16, 1999.

PIETERS, Rik; WEDEL, Michel. Attention capture and transfer in advertising: Brand, pictorial, and text-size effects. Journal of Marketing, v. 68, n. 2, p. 36- 
50, 2004.

PIETERS, Rik; WEDEL, Michel; BATRA, Rajeev. The stopping power of advertising: Measures and effects of visual complexity. Journal of Marketing, v. 74, n. 5, p. 48-60, 2010.

POZHARLIEV, Rumen et. al. Merely Being with You Increases My Attention to Luxury Products: Using EEG to Understand Consumers' Emotional Experience with Luxury Branded Products. Journal of Marketing Research, v. 52, n. 4, p. 546-558, 2015.

PUCCINELLI, Nancy M. et. al. Are men seduced by red? The effect of red versus black prices on price perceptions. Journal of Retailing, v. 89, n. 2, p. 115-125, 2013.

RAGHUBIR, Priya; KRISHNA, Aradhna. Vital dimensions in volume perception: can the eye fool the stomach?. Journal of Marketing research, p. 313-326, 1999.

RAYNER, K.; CASTELHANO, M. Eye movement during reading, scene perception, visual search and while looking at print advertisements. In: WEDEL, M.; PIETERS, R. (Org). Visual Marketing: From Attention to Action. New York: Psychology Press, 2008.

REIMANN, Martin et. al. Aesthetic package design: A behavioral, neural, and psychological investigation. Journal of Consumer Psychology, v. 20, n. 4, p. 431-441, 2010.

ROSA, Pedro. What do your eyes say? Bridging eye movements to consumer behavior. International Journal of Psychological Research, v. 8, n. 2, p. 91104, 2015.

ROSBERGEN, Edward; PIETERS, Rik; WEDEL, Michel. Visual attention to advertising: a segment-level analysis. Journal of consumer research, v. 24, n. 3, p. 305-314, 1997.

SACHARIN, K. Attention! How to Interrupt, Yell, Whisper, and Touch Consumers. New York: John Wiley \& Sons, 2001.

SOARS, Brenda. Driving sales through shoppers' sense of sound, sight, smell and touch. International Journal of Retail \& Distribution Management, v. 37, n. 3, p. 286-298, 2009.

SOJKA, Jane Z.; GIESE, Joan L. Communicating through pictures and words: Understanding the role of affect and cognition in processing visual and verbal information. Psychology \& Marketing, v. 23, n. 12, p. 995-1014, 2006.

SPENCE, Charles et. al. Store atmospherics: A multisensory perspective. Psychology \& Marketing, v. 31, n. 7, p. 472-488, 2014. 
SPIES, Kordelia; HESSE, Friedrich; LOESCH, Kerstin. Store atmosphere, mood and purchasing behavior. International Journal of Research in Marketing, $v$. 14, n. 1, p. 1-17, 1997.

STOLL, Marco; BAECKE, Sebastian; KENNING, Peter. What they see is what they get? An fMRI-study on neural correlates of attractive packaging.Journal of Consumer Behaviour, v. 7, n. 4-5, p. 342-359, 2008.

STORME, Martin et. al. How subjective processing fluency predicts attitudes toward visual advertisements and purchase intention. Journal of Consumer Marketing, v. 32, n. 6, p. 432-440, 2015.

SUMMERS, Teresa A.; HEBERT, Paulette R. Shedding some light on store atmospherics: influence of illumination on consumer behavior. Journal of business research, v. 54, n. 2, p. 145-150, 2001.

TANG, Esther; FRYXELL, Gerald E.; CHOW, Clement SF. Visual and verbal communication in the design of eco-label for green consumer products. Journal of International Consumer Marketing, v. 16, n. 4, p. 85-105, 2004.

UNDERWOOD, Robert L.; KLEIN, Noreen M.; BURKE, Raymond R. Packaging communication: attentional effects of product imagery. Journal of Product \& Brand Management, v. 10, n. 7, p. 403-422, 2001.

VAN ROMPAY, Thomas JL; PRUYN, Ad TH. When Visual Product Features Speak the Same Language: Effects of Shape-Typeface Congruence on Brand Perception and Price Expectations*. Journal of Product Innovation Management, v. 28, n. 4, p. 599-610, 2011.

VALENZUELA, Ana; RAGHUBIR, Priya. Position-based beliefs: The centerstage effect. Journal of Consumer Psychology, v. 19, n. 2, p. 185-196, 2009.

ZHANG, Jie; WEDEL, Michel; PIETERS, Rik. Sales effects of attention to feature advertisements: a Bayesian mediation analysis. Journal of Marketing Research, v. 46, n. 5, p. 669-681, 2009.

WEDEL, Michel; PIETERS, Rik. Eye fixations on advertisements and memory for brands: A model and findings. Marketing science, v. 19, n. 4, p. 297-312, 2000.

WEDEL, M; PIETERS, R. Eye tracking for visual marketing. Hanover: Now Publishers, 2006.

WEDEL, M; PIETERS, R. (Eds.). Visual marketing: From attention to action. New York: Erlbaum, 2008. 
Suele Camatini é mestranda em Administração pela Universidade Federal de Santa Catarina (UFSC), Programa de Pós-Graduação em Administração (PPGAdm/UFSC). É graduada em Administração pela Universidade do Vale do Itajaí, UNIVAL (2009 - 2014).

Martin de La Martiniere Petroll é Professor do Departamento de Ciências da Administração do Centro Socioeconômico da Universidade Federal de Santa Catarina (CAD/CSE/UFSC). Doutor (2013) em Administração pelo Programa de Pós-Graduação em Administração da Universidade Federal do Paraná (UFPR) com período de doutorado-sanduíche na Boston College (Boston/MA/EUA). Mestre (2007) em Administração pelo Programa de Pós-Graduação em Administração da Universidade Federal do Rio Grande do Sul (UFRGS). Graduado (2003) em Administração de Empresas pela Universidade do Vale do Rio dos Sinos (UNISINOS). Professor e orientador de mestrado e doutorado no Programa de Pós-Graduação em Administração (PPGAdm/UFSC) e do Curso de Administração (CADUFSC). Linha de pesquisa: Marketing, Comunicação, Comportamento do Consumidor. Autor de diversos artigos publicados em revistas científicas e anais de eventos nacionais e internacionais. Líder do grupo de pesquisa registrado na UFSC e no CNPq, denominado: Núcleo de Inteligência Competitiva Organizacional em Marketing e Logística (NICO).

Elder Semprebon é Doutor e Mestre em Administração na linha de pesquisa em Estratégia de Marketing e Comportamento do Consumidor pela UFPR, cursou Educational Program na Warrington College of Business University of Florida em Marketing and Entrepreneurship, Especialista em Marketing e Propaganda e Bacharel em Administração pela UEL. Atualmente é professor do Departamento de Administração da Universidade Federal do Paraná (UFPR). Interesses de pesquisa em marketing e branding. 
Recebido em: 10/03/2016; Aceito em: 07/04/2016.

Esta obra foi licenciada com uma Licença Creative Commons.
Rudimar Antunes da Rocha é Professor PhD. do Departamento de Administração, da Universidade Federal de Santa Catarina (UFSC). PósDoutorado em Administração pela Escola de Economia e Gestão da Universidade do Minho (2013-2014 - Braga/Portugal - Bolsa Estágio Sênior (APES), Doutor em Engenharia de Produção pela Universidade Federal de Santa Catarina (2000 - Bolsa CAPES), Mestre em Administração pela Universidade Federal de Santa Catarina (UFSC-1992 - Bolsa CAPES) e Bacharel em Administração pela Universidade Federal de Santa Maria (UFSM-1982). Professor e orientador de mestrado e doutorado no Programa de Pós-Graduação em Administração (PPGAdm/UFSC), Programa de PósGraduação em Administração Universitária (PPGAU/UFSC) e do Curso de Administração (CAD-UFSC). Autor de diversos artigos publicados em revistas científicas e anais de eventos nacionais e internacionais. 